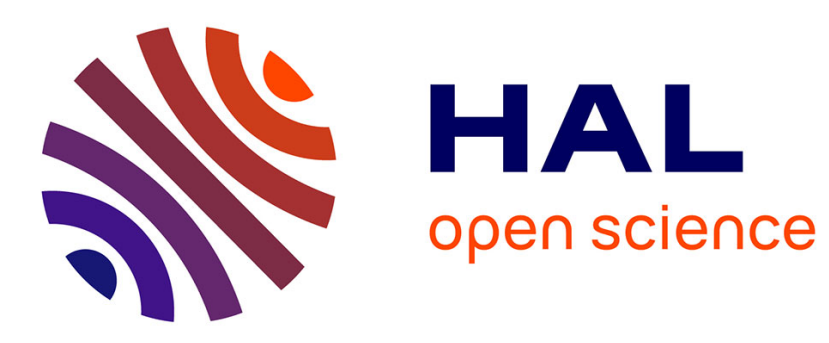

\title{
Origin of mechanical modifications in poly (ether ether ketone)/carbon nanotube composite
}

Ekaterina Pavlenko, François Boyer, Pascal Puech, Philippe Olivier, Andrei

Sapelkin, Stephen King, Richard Heenan, François Pons, Bénédicte Gauthier, Pierre-Henri Cadaux, et al.

\section{To cite this version:}

Ekaterina Pavlenko, François Boyer, Pascal Puech, Philippe Olivier, Andrei Sapelkin, et al.. Origin of mechanical modifications in poly (ether ether ketone)/carbon nanotube composite. Journal of Applied Physics, 2014, 115 (23), pp.234901. 10.1063/1.4883299 . hal-01756989

\section{HAL Id: hal-01756989 \\ https://hal.science/hal-01756989}

Submitted on 3 Apr 2018

HAL is a multi-disciplinary open access archive for the deposit and dissemination of scientific research documents, whether they are published or not. The documents may come from teaching and research institutions in France or abroad, or from public or private research centers.
L'archive ouverte pluridisciplinaire HAL, est destinée au dépôt et à la diffusion de documents scientifiques de niveau recherche, publiés ou non, émanant des établissements d'enseignement et de recherche français ou étrangers, des laboratoires publics ou privés. 


\section{Origin of mechanical modifications in poly (ether ether ketone)/carbon nanotube composite}

Ekaterina Pavlenko, François Boyer, Pascal Puech, Philippe Olivier, Andrei Sapelkin, Stephen King, Richard Heenan, François Pons, Bénédicte Gauthier, Pierre-Henri Cadaux, and Wolfgang Bacsa

Citation: Journal of Applied Physics 115, 234901 (2014); doi: 10.1063/1.4883299

View online: https://doi.org/10.1063/1.4883299

View Table of Contents: http://aip.scitation.org/toc/jap/115/23

Published by the American Institute of Physics

\section{Articles you may be interested in}

Preparation and characterization of the modified PEEK/CNTs-nanocomposites

AIP Conference Proceedings 1779, 040009 (2016); 10.1063/1.4965500

Laser-induced particle size tuning and structural transformations in germanium nanoparticles prepared by stain etching and colloidal synthesis route

Journal of Applied Physics 118, 244303 (2015); 10.1063/1.4939066

Poiseuille geometry shear flow apparatus for small-angle scattering experiments

Review of Scientific Instruments 67, 3158 (1996); 10.1063/1.1147439

Rheology and mechanics of polyether(ether)ketone - Polyetherimide blends for composites in aeronautics AIP Conference Proceedings 1736, 020177 (2016); 10.1063/1.4949752

Physical and electrical characterization of $\mathrm{Ce}-\mathrm{HfO}_{2}$ thin films deposited by thermal atomic layer deposition Journal of Vacuum Science \& Technology B, Nanotechnology and Microelectronics: Materials, Processing, Measurement, and Phenomena 32, $03 \mathrm{D} 103$ (2014); 10.1116/1.4826174

Polymer powders for selective laser sintering (SLS)

AIP Conference Proceedings 1664, 160009 (2015); 10.1063/1.4918516

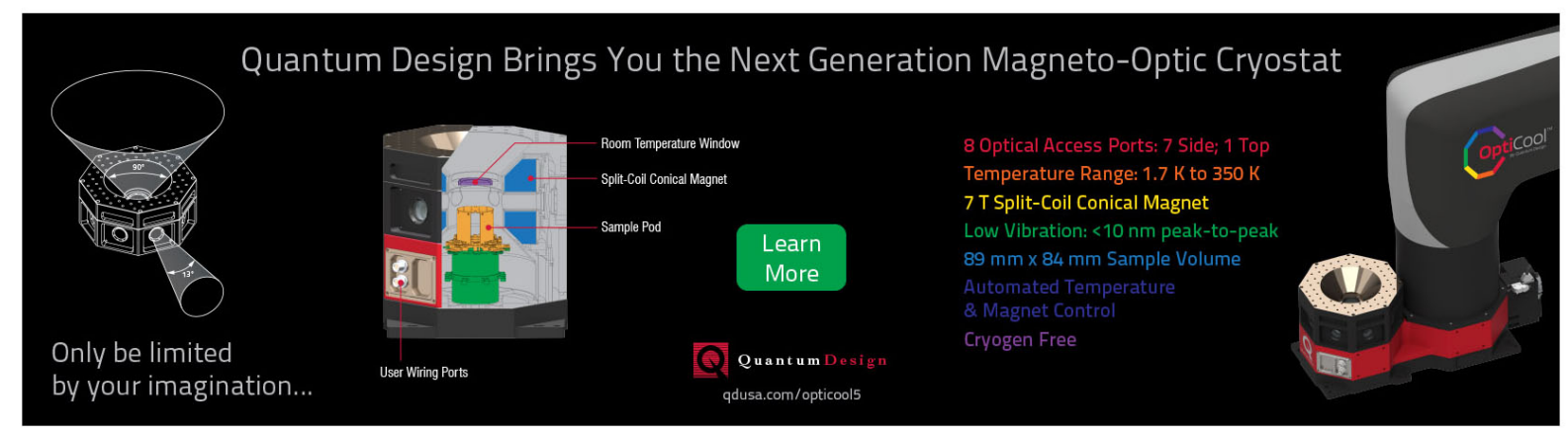




\title{
Origin of mechanical modifications in poly (ether ether ketone)/carbon nanotube composite
}

\author{
Ekaterina Pavlenko, ${ }^{1}$ François Boyer, ${ }^{2}$ Pascal Puech, ${ }^{1}$ Philippe Olivier, ${ }^{2}$ Andrei Sapelkin, ${ }^{3}$ \\ Stephen King, ${ }^{4}$ Richard Heenan, ${ }^{4}$ François Pons, ${ }^{5}$ Bénédicte Gauthier, ${ }^{5}$ \\ Pierre-Henri Cadaux, ${ }^{5}$ and Wolfgang Bacsa ${ }^{1, a)}$ \\ ${ }^{1}$ CEMES-CNRS and University of Toulouse, 29 Jeanne Marvig, 31055 Toulouse, France \\ ${ }^{2}$ Université de Toulouse, Institut Clément Ader, I.U.T. Université Paul Sabatier - 133 C Avenue de \\ Rangueil - B.P. 67701, 31077 Toulouse CEDEX 4, France \\ ${ }^{3}$ School of Physics and Astronomy, Queen Mary, University of London, Mile End Road, E1 4NS London, \\ United Kingdom \\ ${ }_{4}^{4}$ ISIS Facility, Rutherford Appleton Laboratory, Chilton, OX11 0QX Didcot, United Kingdom \\ ${ }^{5}$ AIRBUS FRANCE (B.E.M\&P Toulouse), 316 Route de Bayonne, 31060 Toulouse, France
}

(Received 29 April 2014; accepted 2 June 2014; published online 16 June 2014)

\begin{abstract}
Variations in the hardness of a poly (ether ether ketone) beam electrically modified with multiwalled carbon nanotubes (MWCNT, 0.5\%-3\%) are investigated. It is shown that both rupture and hardness variations correlate with the changes in carbon nanotube concentration when using micro indentation and extended Raman imaging. Statistical analysis of the relative spectral intensities in the Raman image is used to estimate local tube concentration and polymer crystallinity. We show that the histogram of the Raman D band across the image provides information about the amount of MWCNTs and the dispersion of MWCNTs in the composite. We speculate that we have observed a local modification of the ordering between pure and modified polymer. This is partially supported by small angle neutron scattering measurements, which indicate that the agglomeration state of the MWCNTs is the same at the concentrations studied. (C) 2014 AIP Publishing LLC.
\end{abstract}

[http://dx.doi.org/10.1063/1.4883299]

\section{INTRODUCTION}

Poly (Ether Ether Ketone) (PEEK) is a high performance polymer with excellent thermal stability and mechanical properties used in aerospace industry. ${ }^{1}$ While the mechanical properties of the polymer depend on its crystallinity, typical PEEK processing conditions yield 30\% crystallinity. Sandler et al. ${ }^{2}$ showed that PEEK adheres well to carbon nano fibers (CNF) and crystallinity of 30\% with 15 wt. \% CNF was measured. Using multi-walled carbon nanotubes (MWCNT), it has become possible to reduce filler content at percolation (1-5 wt. \%) and improve the electrical conductivity. ${ }^{3-5}$ The distribution of CNTs in the polymer matrix can be assessed by transmission electron microscopy or scanning electron microscopy. Electron microscopy is useful to image tube alignment due to shear flow ${ }^{6,7}$ but is unsuitable to estimate tube concentration due to ambiguity in the image interpretation since PEEK can form thin filaments, which are difficult to distinguish from nanotubes as it can be seen in Fig. 1.

To determine variations in tube concentration in polymers, we use Raman spectroscopy. Raman spectroscopy is a versatile tool to detect the amount of carbon nanotubes and their alignment at the micrometer scale. ${ }^{8-10}$ Optical spectroscopy is non-invasive and requires no specific sample preparation but is limited by the optical penetration depth. It has been shown that the use of Fourier Transform Raman

\footnotetext{
a) Author to whom correspondence should be addressed. Electronic mail: wolfgang.bacsa@cemes.fr.
}

spectroscopy is limited for CNF in PEEK composites ${ }^{11}$ due to strong background luminescence and low anti-Stokes scattering. To avoid too large luminescence and overexposure with the illuminating laser beam, we use laser excitation at $785 \mathrm{~nm}$ where vibrational bands of both CNTs and PEEK can be observed. Alternatively, picosecond time-resolved Raman spectroscopy in the visible range which rejects luminescence has been successfully applied to PEEK. ${ }^{12}$ Small angle X-ray and neutron scattering (SAXS/SANS) are complementary techniques able to observe the distribution of CNTs in polymer composites. SAXS and SANS provide information about CNT bundling and the morphology of the polymer. ${ }^{13,14}$ The CNT distribution can be imaged by Raman mapping of the composite surface by analyzing quantitatively the Raman vibrational bands. So far, Raman spectral mapping has not been fully exploited to image the distribution of CNT in polymer composites. ${ }^{15}$ Even if the uncertainty is large with one spectrum, the statistical analysis reduces the uncertainty by a factor by $\sqrt{n}$ for $\mathrm{n}$ measurements. As our maps deal with hundreds of spectra, the extracted values are significant.

To better understand hardness variations in the composite, we first report tensile strain measurements as a function of carbon nanotube content in PEEK. We then use differential scanning calorimetric measurements (DSC) and micro indentation to determine the crystallinity of the polymer and the hardness. We then employ Raman imaging to determine the amount of CNTs and their dispersion. Finally, SANS measurements indicate that the polymer structure is influenced by the presence of carbon nanotubes. 


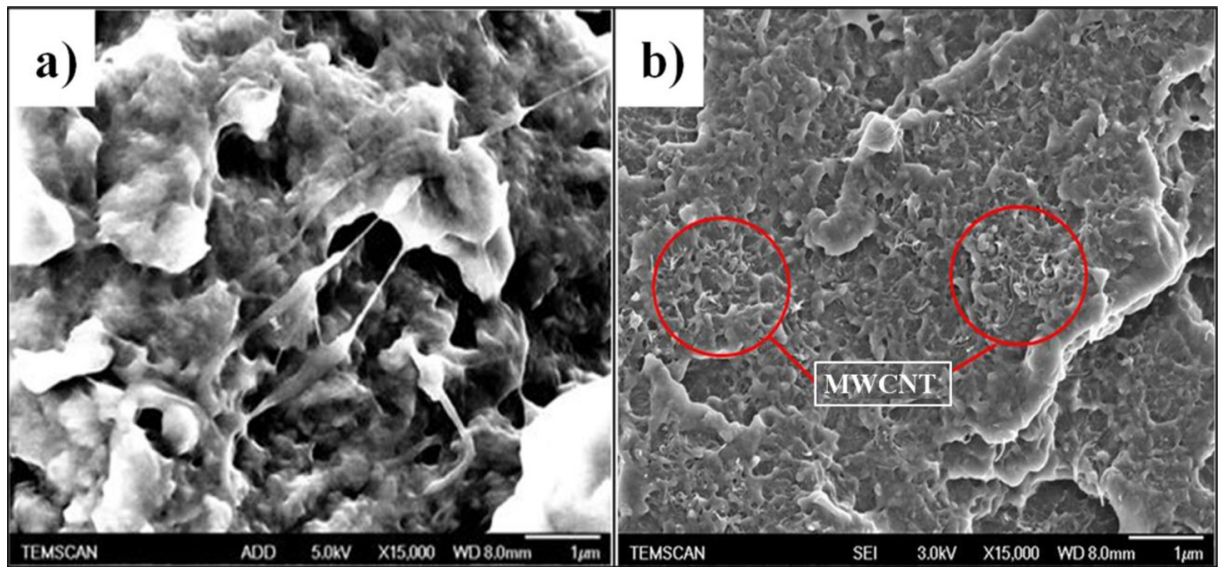

FIG. 1. SEM micrographs from fractured surfaces of (a) unfilled PEEK and (b) PEEK/1\%MWCNT.

\section{EXPERIMENTAL}

The composite was prepared from PEEK fine powder (grade 2000, EVONIK DEGUSSA GmbH ${ }^{16}$ ) mixed with dry MWCNTs (Graphistrength C100, ARKEMA, average carbon purity: 90\%, diameter: 9-30 nm, length-0.1-10 $\mu \mathrm{m}$, number of layers: 5-15). Fig. 3(a) shows a typical Raman spectrum of the ARKEMA C100 MWNTs. A twin screw extruder ${ }^{15}$ was used at the temperature of $380^{\circ} \mathrm{C}$ to mix the tubes into the polymer. A bone shaped tensile test beam was manufactured using an injection press (OPSYS from DK-Le Guen Hemidy) by heating the composite to $400^{\circ} \mathrm{C}$. Stress-strain curves were measured using an INSTRON 8501 instrument and DSC measurements were carried out using a Q100 instrument from TA Instruments Corporation. All reported DSC values are averaged values of three measurements. Nano-indentations were made using a Nano Hardness Tester from CSM Instrument Corporation after the samples were polished. A Berkovich indentation tip was used at an indentation speed of $100 \mathrm{mN} / \mathrm{min}$. All measurements were carried out according to standard ISO 14577-4, which requires that the surface roughness value needs to be less than $5 \%$ of the maximum penetration depth $(4000 \mathrm{~nm})$. Raman spectroscopy was carried out on an XPloRa instrument from Jobin-Yvon-Horiba with a $\times 100$ optical objective and a motorized XY-Table. The $785 \mathrm{~nm}$ laser excitation wavelength was used at low laser power $(0.4 \mathrm{~mW})$. SANS measurements were performed on the LOQ and SANS2D diffractometers at the ISIS Facility, Oxfordshire, UK. ${ }^{17}$ These are "white-beam" time-of-flight instruments covering scattering vector ranges of $0.009 \leq Q$ $\leq 1.2 \AA^{-1}(0.5 \mathrm{~m}$ and $4 \mathrm{~m}$ sample-detector distances, wavelengths $2.2 \leq \lambda \leq 10 \AA)$ and $0.0015 \leq Q \leq 0.19 \AA^{-1}(12 \mathrm{~m}$ sample-detector distance, $150 \mathrm{~mm}$ detector offset, wavelengths $1.5 \leq \lambda \leq 12.5 \AA$ ), respectively, where $Q=4 \pi / \lambda$ $\sin (\theta / 2)$ and $\theta$ is the scattering angle. Each raw scattering data set was corrected for the detector efficiencies, sample transmission, and background scattering and converted to scattering cross-section data $(\partial \Sigma / \partial \Omega$ vs. Q) using the instrument-specific software. ${ }^{18}$ These data were placed on an absolute scale $\left(\mathrm{cm}^{-1}\right)$ using the scattering from a standard sample (a solid blend of hydrogenous and perdeuterated polystyrene) in accordance with established procedures. ${ }^{19}$

\section{RESULTS AND DISCUSSION}

\section{A. Tensile strain measurements}

The tensile strain measurements have been carried out on the test beams. Fig. 2 shows the stress strain curve for PEEK composites containing 0.5-3.0 wt. \% CNTs and the PEEK matrix without CNTs. The introduction of MWCNTs into PEEK results in drastic change in the PEEK mechanical behavior. The behavior of PEEK changes from ductile $\left(\varepsilon_{\text {fracture }}=28.6 \%\right)$ with no tubes to semi-brittle $\left(\varepsilon_{\text {fracture }}\right.$ $=5 \%$ ) when filled with $0.5 \mathrm{wt}$. $\%$ MWCNT. The modification of the ductile regime with filler particles in PEEK has also been observed for $\mathrm{CNF}^{1}$ and $\mathrm{SiO}_{2}$ nanoparticles. ${ }^{20}$ The tensile modulus average value $(\mathrm{E})$ increases by $7 \%$ between PEEK without tubes and with 2 wt. \% MWCNTs. The ultimate tensile stress value at sample break $\left(\sigma_{t}^{u l t}\right)$ goes up from $78 \mathrm{MPa}$ for PEEK without tubes to $96 \mathrm{MPa}$ with $0.5 \mathrm{wt}$. \% MWCNTs. Once filled with MWCNT the nanocomposites exhibit ultimate tensile stress values laying between 88 and $96 \mathrm{MPa}$ independent of the amount of MWCNT present in the composite. Table I shows the crystallization $\mathrm{X}_{\mathrm{c}}$ calculated from the peak enthalpies normalized by the actual weight fraction of PEEK

$$
X_{c}=\frac{\Delta h_{c}}{\Delta h_{c}^{0} W_{\text {polymer }}} \times 100,
$$

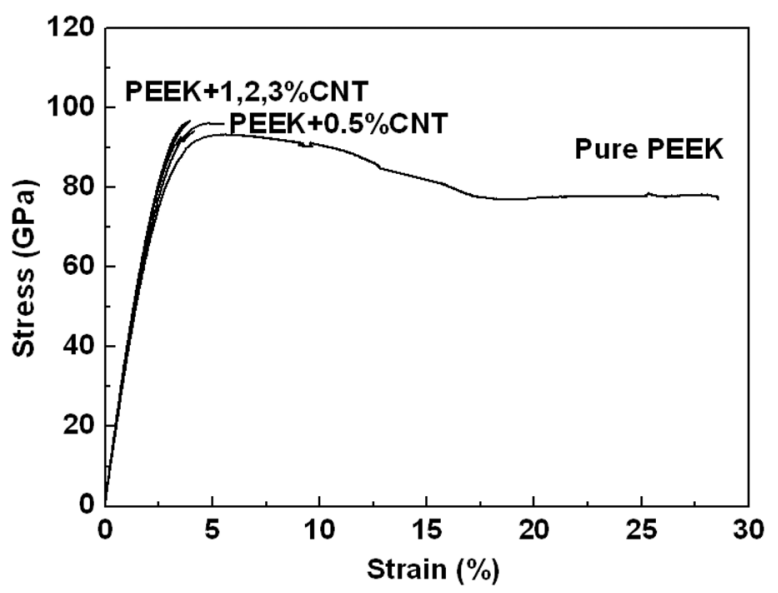

FIG. 2. Stress/stain curves with different amounts of CNTs in PEEK and comparison with the PEEK matrix. 
TABLE I. Degree of crystallinity of PEEK nanocomposite.

\begin{tabular}{lcc}
\hline \hline Sample & $\mathrm{X}_{\mathrm{c}}(\%)$ centre & $\mathrm{X}_{\mathrm{c}}(\%)$ edge \\
\hline Pure PEEK & $31.5 \pm 1.4$ & $31.6 \pm 0.5$ \\
PEEK 0.5\% CNT & $33.1 \pm 1.8$ & $32.9 \pm 1.9$ \\
PEEK 1\% CNT & $31.6 \pm 2.0$ & $31.4 \pm 0.6$ \\
PEEK 2\% CNT & $33.7 \pm 1.1$ & $31.0 \pm 1.2$ \\
\hline \hline
\end{tabular}

$\Delta h_{c}^{0}$ is $130 \mathrm{~J} / \mathrm{g}$ (Ref. 21) and $\mathrm{W}_{\text {polymer }}$ is the weight fraction of the polymer-matrix. Experiments were conducted from a sample taken at the edge and the centre of the beam. The measurements show that the amount of crystallinity $(32 \%)$ is about the same, independently of CNTs content (see in Table I). It has been shown that the presence of carbon fillers (i.e., short fibers) changes the mechanical behavior irrespective of the crystallinity of the PEEK matrix. ${ }^{22}$ The measurements here show that the amount of crystallinity $(32 \%)$ is the same in the volume of beam and between the core and the outer surface of the beam. This is consistent with reports which showed that the presence of CNTs increases the crystallization temperature of PEEK but does not influence the crystallinity. ${ }^{23}$ We conclude, therefore, that the reduction of the ductile regime is not caused by any increased polymer crystallinity.

\section{B. Nano-indentation}

The elastic reduced modulus, $\mathrm{E}_{\mathrm{IT}}{ }^{*}$, is determined by

$$
E_{I T}^{*}=\frac{\sqrt{\pi}}{2} \cdot \frac{S}{\sqrt{A_{p}}} \quad \text { or } \quad \frac{1}{E_{I T}^{*}}=\frac{\left(1-\nu^{2}\right)}{E_{I T}}+\frac{\left(1-\nu_{i}^{2}\right)}{E_{i}}
$$

where subscript $i$ corresponds to the specific properties of the indenter, $\nu$ the Poisson's ratio, $A_{p}$ the residual area, and $S$ the stiffness of the contact. The manufacturer gives for the intender: $\nu_{\mathrm{i}}=0.07$ and $\mathrm{E}_{\mathrm{i}}=1141 \mathrm{GPa}$. To see whether
TABLE II. Micro-hardness at two positions.

\begin{tabular}{lcc}
\hline \hline Sample & Edge micro-hardness $(\mathrm{GPa})$ & Core micro-hardness $(\mathrm{GPa})$ \\
\hline Pure PEEK & $4.16 \pm 0.07$ & $4.16 \pm 0.07$ \\
PEEK 0.5\% & $4.00 \pm 0.05$ & $4.52 \pm 0.05$ \\
PEEK 1\% & $3.86 \pm 0.05$ & $4.34 \pm 0.05$ \\
PEEK 2\% & $3.92 \pm 0.15$ & $4.58 \pm 0.15$ \\
PEEK 3\% & $4.00 \pm 0.10$ & $4.28 \pm 0.10$ \\
\hline \hline
\end{tabular}

fracture is caused by inhomogeneous distribution of CNTs in the polymer, we have carried out micro-indentation experiments. The measured micro-hardness on the two sets of samples is shown in Table II. The measurements reveal that the edges are less hard than the core of the composite. The micro-hardness varies by $10 \%-15 \%$ between the centre and the edge of the beam. We have verified that PEEK without CNTs shows no difference in hardness at the edge and the centre of the beam. This result suggests that the variation in hardness is caused by variation in the CNT content within the beam.

\section{Raman spectroscopy}

We have used Raman spectroscopy to determine directly the CNT content at different locations of the beam. Four samples with different amounts of nanotubes $(0,0.5,1$, and 2 wt. \%) in a polymer matrix were cut parallel with respect to the direction of the extrusion. Fig. 3(b) shows the locations where Raman images were recorded. To determine the amount of CNTs at three different places, we recorded Raman images of size $400 \mu \mathrm{m} \times 400 \mu \mathrm{m}$. Raman spectra were recorded every $4.6 \mu \mathrm{m}$ with focal spot size of $1 \mu \mathrm{m}(84 \times 84=7056$ spectra $)$. Figs. 3(c) and 3(d) show examples of Raman spectra obtained for pure PEEK and PEEK with CNTs.

Three Raman bands are observed: ${ }^{24}$ the $\mathrm{D}, \mathrm{G}$, and $\mathrm{P}$ bands. The disorder induced $\mathrm{D}$ band at approximately $1300 \mathrm{~cm}^{-1}$ shifts with laser energy and is caused by double
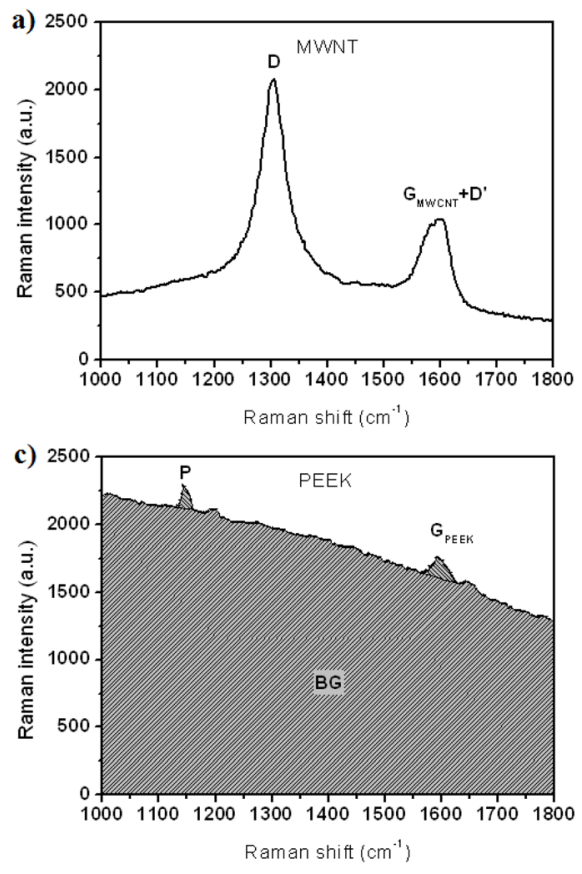

b)
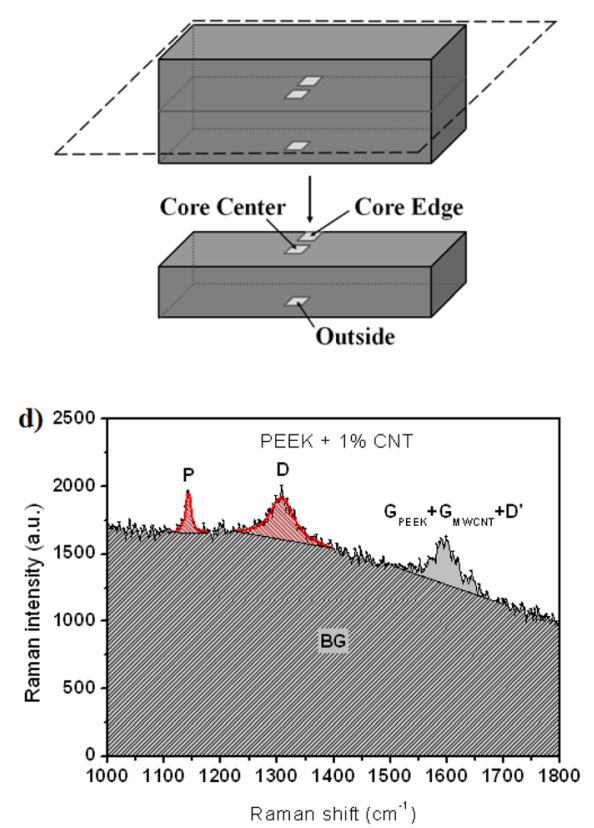

FIG. 3. (a) A typical Raman spectrum of ARKEMA MWNTs, (b) locations on the beam where Raman measurements were performed: in the middle of the bar (outside), at the center of the core, and at the edge of the core; (c) and (d) reprehensive Raman spectra for PEEK only and PEEK with MWCNT. 
BG

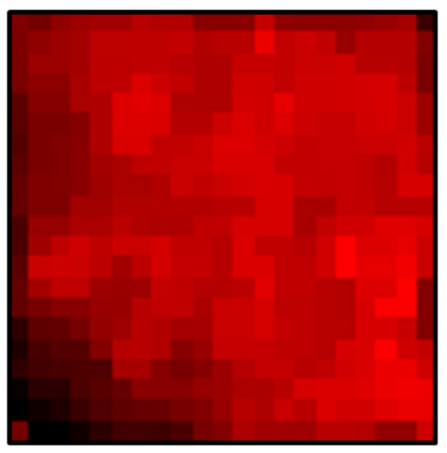

D

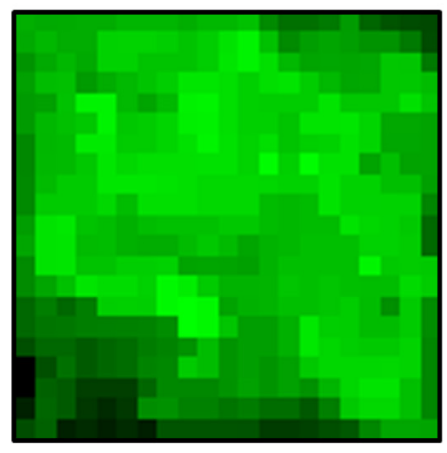

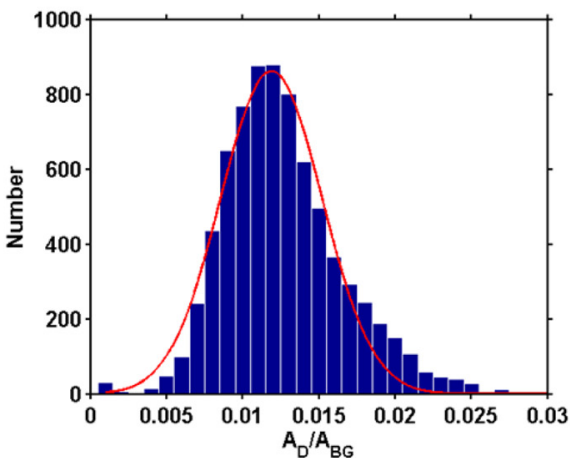

FIG. 4. Raman map of background (BG), D band, and deduced histogram of relative intensity of D band.

resonance scattering. The $\mathrm{G}$ band located at $1580 \mathrm{~cm}^{-1}$ is characteristic for $\mathrm{sp}^{2}$ bonded carbon. A shoulder at the higher energy side of the $G$ band, the $D^{\prime}$ band is due to defect induced double resonance scattering. It has been observed that the intensity of the $\mathrm{D}$ and $\mathrm{D}^{\prime}$ bands remains constant, while the intensity of the $\mathrm{G}$ band varies with laser energy. ${ }^{25}$ The $\mathrm{G}$ band is found to be less intense in the near-infrared spectral region when compared to the visible spectral region. A narrow band at $1144 \mathrm{~cm}^{-1}$, referred from here on as the $\mathrm{P}$ band, corresponds to the asymmetric C-O-C stretch vibration in the PEEK polymer. ${ }^{26}$ In pure PEEK, one can also observe a less intense $G$ band (we keep this name for simplicity) due to the presence of $\mathrm{sp}^{2}$ bonded carbon in the benzene ring of the polymer. The background in the PEEK spectra is caused by luminescence of PEEK and by the Raman signal of the amorphous PEEK polymer. Since PEEK does not have any $\mathrm{D}$ band, we use the $\mathrm{D}$ band as an indicator of the presence of CNT. The D band is fitted with a Lorentzian line shape and the $\mathrm{D}$ band intensity and background signal are used for statistical analysis (Fig. 4). For each Raman map, we have generated a histogram of the ratio of the D and PEEK band integrated intensity with respect to the background signal: $A_{D} / A_{B G}, A_{P E E K} / A_{B G}$. The background signal is stable within the mapped area. The line under the peak (Figs. 3(c) and 3(d)) shows the limit of the background signal. We recorded several Raman maps for each location and generated an averaged histogram of the relative band intensities. Even if each Raman spectrum is noisy, the statistical analysis reduces the uncertainty by a factor of 84 leading to perfectly interpretable data. While the position of the maximum in the histogram gives a measure of the CNT content, the width of the histogram or standard deviation gives a measure of the dispersion of the tubes. Our statistical analysis assumes that the oscillation strength variation due to the tube surrounding and organization is sufficiently small and can be ignored. We note that standard deviation in Fig. 4 should not be confused with the noise of one Raman spectrum. The standard deviation in the histogram of the Raman map is also referred to as image noise. We note that the statistical error, which limits the statistical analysis, is less than the extracted image noise. From the literature, it is known that the $\mathrm{P}$ band does not change in amorphous and crystalline PEEK $^{27}$ but increases in intensity $(\times 1.5)$ when approaching the melting temperature $\left(300^{\circ} \mathrm{C}\right)$. The $\mathrm{P}$ band is, therefore, expected to be uniform across the Raman map. However, some variation in the ratio of the $\mathrm{P}$ band and the background signal was found, which we attribute to be induced by the presence of CNTs. The presence of CNTs can modify the optical field and structure in their neighborhood and as a result change the intensity of the $\mathrm{P}$ band.

The position of the maximum of the histogram measures the amount of CNTs and the standard deviation gives a measure of the dispersion of CNTs in the composite. The maxima of histograms and standard deviation of the relative D band intensities as a function of CNT content are shown in Table III. We observe that the D band intensity increases with increasing amount of CNTs in the composite as expected but at the same time the D band histogram gets broader, while the broadening/mean ratio remains constant showing clearly that the distribution of the tubes is homothetic with different CNT concentration. With an average diameter of $10 \mathrm{~nm}$ and 10 walls, each MWCNT absorbs roughly $1-(0.977)($ Ref. 20$)=0.4($ Ref. 28$)$ of the incident light when assuming the refraction index of graphene (reduction of $2.3 \%$ after each layer). As a consequence, with a layer of $1 \mu \mathrm{m}$ with $1 \mathrm{wt}$. \% CNTs, the transmitted light represents $40 \%$ of the incident light. The Raman probe depth due to the light path in the material (direct and return) is less than $1 \mu \mathrm{m}$. As we do not use a confocal arrangement, the probe depth with our experiment is thus limited by the absorption of the nanotubes and is proportional to the concentration. As a consequence, we assume that the $\left\langle A_{D}\right\rangle$ value is constant, while the $\left\langle\mathrm{A}_{\mathrm{BK}}\right\rangle$ is proportional to the measured volume (spot size multiplied by the Raman probe depth) and the $\left\langle\mathrm{A}_{\mathrm{D}}\right\rangle /\left\langle\mathrm{A}_{\mathrm{BK}}\right\rangle$ ratio is proportional to the CNT concentration. The ratio of the standard deviation and mean value is a

TABLE III. Position of the maximum of the histogram of the relative Raman D and P band intensity and standard deviation as a function of CNT content.

\begin{tabular}{lcccc}
\hline \hline Sample & $\begin{array}{c}\left\langle\mathrm{A}_{\mathrm{D}} / \mathrm{A}_{\mathrm{BG}}\right\rangle \\
\text { mean }\end{array}$ & $\begin{array}{c}\left\langle\mathrm{A}_{\mathrm{D}} / \mathrm{A}_{\mathrm{BG}}\right\rangle \\
\text { broadening/mean }\end{array}$ & $\begin{array}{c}\left\langle\mathrm{A}_{\mathrm{P}} / \mathrm{A}_{\mathrm{BG}}\right\rangle \\
\text { mean }\end{array}$ & $\begin{array}{c}\left\langle\mathrm{A}_{\mathrm{P}} / \mathrm{A}_{\mathrm{BG}}\right\rangle \\
\text { broadening/mean }\end{array}$ \\
\hline Pure PEEK & 0.0001 & 0.08 & 0.00093 & 0.26 \\
PEEK 0.5\% CNT & 0.0064 & 0.32 & 0.00090 & 0.40 \\
PEEK 1\% CNT & 0.0173 & 0.40 & 0.00212 & 0.30 \\
PEEK 2\% CNT & 0.0494 & 0.63 & 0.00301 & 0.31 \\
\hline \hline
\end{tabular}


measurement of the distribution normalized by the volume (the mean value is proportional to the volume at a given concentration). Consequently, this value is nearly constant for all concentration since the mixing process is the same at all concentrations (same screw speed and same injection parameters). Interestingly, the PEEK band increases with increasing amount of CNTs in the composite. CNTs are known to act as nano-antennas. ${ }^{29}$ The CNT absorption of the optical field is higher than the polymer matrix. This increases the local optical field around the CNTs and as a result the Raman signal of the surrounding matrix is intensified. ${ }^{30}$ Furthermore, the smooth surface of CNTs can lead to local ordering of the polymer molecules, which can also increase the Raman signal of PEEK. From the DSC measurements, we know that the average crystallinity does not change with the presence of CNTs but it is still possible that CNTs change the nature of the crystallization. This is reflected in the reduction of ductility with $15 \%$ of CNF and with $1 \%$ of CNTs discussed above. This suggests that the presence of CNTs changes the structural flexibility of the matrix due to a structuring of PEEK in contact with or near the CNTs. This is consistent with the literature reports of epitaxial growth of polymer crystallites around CNTs with no large modification of the average crystallinity. ${ }^{31}$

We carried out the same Raman analysis on maps at the core and the edge of the composite beam. Surface areas of $200 \mu \mathrm{m} \times 200 \mu \mathrm{m}$, in steps of $10 \mu \mathrm{m}$ for the PEEK $+1 \mathrm{wt}$. \% CNTs sample were Raman mapped and histograms for the D band and the $\mathrm{P}$ band were deduced. The average values are shown in Table IV. The statistical analysis of the intensity of the D band shows that the concentration of CNTs is higher in the center of the core. We conclude that the difference in hardness observed with the nano-indentation measurements at the core and at the edge of the composite beam correlates with the amount of CNTs present in the two different locations. Two hypotheses can be made here: the tensile strain variations are either caused by a change in CNT concentration or a change in the agglomeration of CNTs. In both cases, it could lead to a decrease of the modulus and to a change in the ratio $\left.\left\langle\mathrm{A}_{\mathrm{P}}\right\rangle\right\rangle /\left\langle\mathrm{A}_{\mathrm{BG}}\right\rangle$. Since the ratio of standard deviation and mean value of the histogram does not change much between the edge and the core, we suspect that this variation is linked to the concentration variation rather than to tube bundling. The higher CNT concentration at the core of the beam results in higher hardness at the core of the beam. Possibly, the injection molding process but also the temperature history of different part of the beam influences local CNT dispersion resulting in variations in hardness.

TABLE IV. Result of statistical evaluation of relative Raman D and P band intensity for $1 \%$ CNTs in the center and the edge of the sample.

\begin{tabular}{lcccc}
\hline \hline Sample & $\begin{array}{c}\left\langle\mathrm{A}_{\mathrm{D}} / \mathrm{A}_{\mathrm{BG}}\right\rangle \\
\text { mean }\end{array}$ & $\begin{array}{c}\left\langle\mathrm{A}_{\mathrm{D}} / \mathrm{A}_{\mathrm{BG}}\right\rangle \\
\text { broadening/mean }\end{array}$ & $\begin{array}{c}\left\langle\mathrm{A}_{\mathrm{P}} / \mathrm{A}_{\mathrm{BG}}\right\rangle \\
\text { mean }\end{array}$ & $\begin{array}{c}\left\langle\mathrm{A}_{\mathrm{P}} / \mathrm{A}_{\mathrm{BG}}\right\rangle \\
\text { broadening/mean }\end{array}$ \\
\hline Core-centre & 0.0173 & 0.25 & 0.0021 & 0.30 \\
Edge & 0.0142 & 0.26 & 0.0016 & 0.37 \\
\hline \hline
\end{tabular}

\section{SANS}

We have conducted SANS measurements to probe the structural organization in the composite at intermediate length scales $(\sim 1 \mathrm{~nm}-400 \mathrm{~nm})$. Some representative SANS data are shown in Fig. 5. The data between $0.2 \leq Q$ $\leq 1.2 \AA^{-1}$ are essentially a flat background, consistent with the persistence length of PEEK. The prominent crystal peaks are at $Q>1.2 \AA^{-1} .^{32}$ In the pure PEEK samples, the SANS primarily arises from the difference between the amorphous and crystalline regions. The broad peak centered at $Q=0.04 \mathrm{~A}^{-1}$, which corresponds to a length scale $(d)$ of $16 \mathrm{~nm}$ on applying the Bragg relation, $d=2 \pi / Q$, is characteristic of the two-phase nature of the spherulite sub-structure in PEEK. ${ }^{32,33}$ The limiting behavior of these data at lower $Q$ values can probably be attributed to the size of the spherulites themselves; the data fit quite nicely to a model for polydisperse spheres of average radius $28 \mathrm{~nm}$ with $40 \%$ polydispersity, but does not fit to a model for Gaussian chains (fits not shown for clarity).

When CNTs are introduced into the PEEK matrix, the SANS primarily arises from the CNTs rather than the polymer, and so the features discussed above are suppressed. Instead, power-law scattering manifests itself. The neutron scattering length density of the CNTs is $\sim 4-5$ and that of the hydrogenous PEEK is $\sim 2$ (in units of either $10^{-6} \mathrm{~A}^{-2}$ or $10^{10} \mathrm{~cm}^{-2}$ ). In the $Q$ range $0.002-0.02 \AA^{-1}$, the exponent characterizing this power law is $\sim 2.2$, consistent with a fractal, network-like, distribution of the CNTs. ${ }^{13}$ The shoulder centered at $Q \sim 0.02 \AA^{-1}$ is likely from the underlying form factor from the nanotubes. In the $Q$ range $0.05-0.1 \AA^{-1}$, the power law exponent is $\sim 1$, and this likely reflects the crossover from the aggregate structure to that of individual nanotubes. Applying the Bragg relation this time gives $d=2 \pi / 0.05=126 \AA$ or $\sim 13 \mathrm{~nm}$. This is rather too short to be an estimate of the length of the nanotubes, but is typical of the overall diameter of MWCNTs. The lower $Q$ limit of the $Q^{-1}$ region is, therefore, masked by the aggregate structure. Indeed, it can be seen that the SANS intensity approximately scales with the CNT loading of the matrix. Whilst these data cannot say anything definitive about the effect of the CNTs

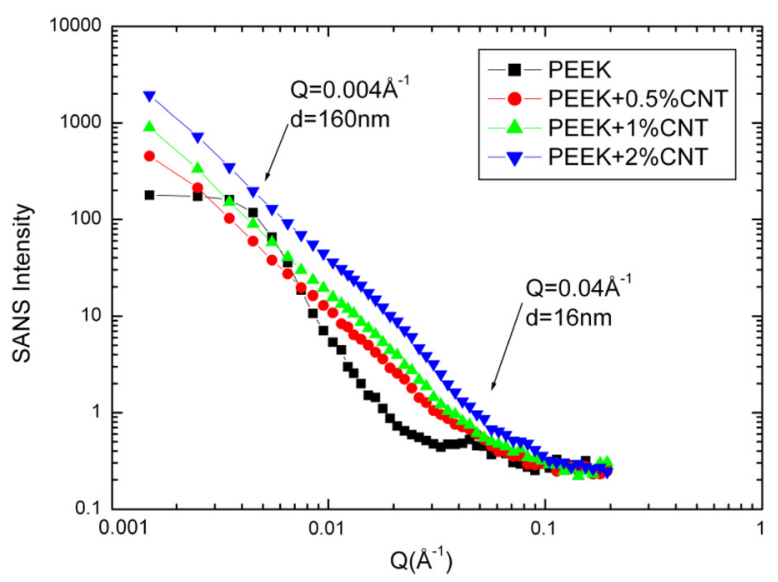

FIG. 5. SANS intensity versus Q for pure PEEK and nanocomposite with $0.5 \%, 1 \%$, and $2 \%$ of CNTs. 
on the structure of the PEEK chains. The similar form of the SANS data for the CNT-loaded PEEK samples is evidence that the aggregate structure of the CNTs is similar at all three CNT concentrations studied.

\section{CONCLUSIONS}

We have investigated the variation in hardness of PEEK composite beams containing $0.5-2 \mathrm{wt}$ \% of MWCNTs. Tensile strain measurements show that the ductile regime of the composite is reduced through the incorporation of MWCNTs in the PEEK matrix. Nano indentation measurements reveal hardness variations at the core and the edge of the beam, while statistical evaluation of two Raman bands associated with PEEK and MWCNTs indicate that the MWCNT concentration is higher in the core as compared to the edge of the beam. We use histograms of the relative intensity of the D band across a Raman map to measure the amount of MWCNTs and their dispersion. We find that variations in MWCNT concentration lead to variations in hardness in MWCNT/PEEK composites. While the average crystallinity of the polymer is not affected by low concentrations of MWCNTs, they appear to influence organization of the polymer around the tube affecting the overall ductility of the composite beam. SANS measurements confirm this interpretation. Two peaks in the SANS spectrum disappear when CNTs are present even as low as $0.5 \%$ of CNT incorporated in PEEK revealing matrix structural changes at the nanometric scale.

\section{ACKNOWLEDGMENTS}

We thank the STFC ISIS Facility for the provision of neutron beam time under the Xpress measurement program (Experiment No. XB139027).

This work was supported by "Programme Investissements d'Avenir" (ANR-11-IDEX-0002-02, reference ANR-10-LABX-0037-NEXT).

The authors would like to acknowledge C. Derail, F. Leonardi and S. Dagreou from IPREM, University of Pau for the manufacturing of PEEK/nanotube granulates.

${ }^{1}$ J. Seferis, "Polyetheretherketone (PEEK): Processing-structure and properties studies for a matrix in high performance composites," Polym. Compos. 7, 158 (1986).

${ }^{2}$ J. Sandler, P. Werner, M. S. P. Shaffer, V. Demchuk, V. Altstädt, and A. H. Windle, "Carbon-nanofibre-reinforced poly(ether ether ketone) composites," Composites 33, 1033-1039 (2002).

${ }^{3}$ W. Bauhofer and J. Z. Kovacs, "A review and analysis of electrical percolation in carbon nanotube polymer composites," Compos. Sci. Technol. 69, 1486-1498 (2009).

${ }^{4}$ D. S. Bangarusampath, H. Ruckdäschel, V. Altstädt, J. K. W. Sandler, D. Garray, and M. S. P. Shaffer, "Rheological and electrical percolation in melt-processed PEEK/multi-wall carbon nanotube composites," Chem. Phys. Lett. 482, 105-109 (2009).

${ }^{5}$ M. Mohiuddin and S. V. Hoa, "Temperature dependent electrical conductivity of CNT-PEEK composites," Compos. Sci. Technol. 72, 21 (2011).

${ }^{6}$ M. C. Paiva, B. Zhou, K. A. S. Fernando, Y. Lin, J. M. Kennedy, and Y.-P. Sun, "Mechanical and morphological characterization of polymercarbon nanocomposites from functionalized carbon nanotubes," Carbon 42, 2849-2854 (2004).
${ }^{7}$ Y. Dror, W. Salalha, R. L. Khalfin, Y. Cohen, A. L. Yarin, and E. Zussman, "Carbon nanotubes embedded in oriented polymer nanofibers by electrospinning," Langmuir 19, 7012 (2003).

${ }^{8}$ V. Tishkova, P.-I. Raynal, P. Puech, A. Lonjon, M. Le Fournier, P. Demont, E. Flahaut, and W. Bacsa, "Electrical conductivity and Raman imaging of double wall carbon nanotubes in a polymer matrix," Compos. Sci. Technol. 71, 1326-1330 (2011).

${ }^{9}$ Q. Wang, J. Dai, W. Li, Z. Wei, and J. Jiang, "The effects of CNT alignment on electrical conductivity and mechanical properties of SWNT/epoxy nanocomposites," Compos. Sci. Technol. 68, 1644-1648 (2008).

${ }^{10}$ W. Zhou, J. Vavro, C. Guthy, K. I. Winey, J. E. Fischer, L. M. Ericson, S. Ramesh, R. Saini, V. A. Davis, C. Kittrell, M. Pasquali, R. H. Hauge, and R. E. Smalley, "Single wall carbon nanotube fibers extruded from superacid suspensions: Preferred orientation, electrical, and thermal transport," J. Appl. Phys. 95, 649 (2004).

${ }^{11}$ G. Ellis, M. Naffakh, C. Marco, and P. J. Hendra, "Fourier transform Raman spectroscopy in the study of technological polymers Part 1: Poly (aryl ether ketones), their composites and blends," Spectrochim. Acta, Part A 53, 2279-2294 (1997).

${ }^{12}$ N. Everall, T. Hahn, P. Matousek, A. W. Parker, and M. Towrie, "Picosecond time-resolved Raman spectroscopy of solids: Capabilities and limitations for fluorescence rejection and the influence of diffuse reflectance," Appl. Spectrosc. 55(12), 1701-1708 (2001).

${ }^{13}$ M. C. García-Gutiérrez, A. Nogales, J. J. Hernández, D. R. Rueda, and T. A. Ezquerra, "X-ray scattering applied to the analysis of carbon nanotubes, polymers and nanocomposites," Opt. Pura Apl. 40, 195-205 (2007).

${ }^{14}$ A. A. Golosova, J. Adelsberger, A. Sepe, M. A. Niedermeier, P. Lindner, S. S. Funari, R. Jordan, and Ch. M. Papadakis, "Dispersions of polymermodified carbon nanotubes: A small-angle scattering investigation," J. Phys. Chem. C 116, 15765-15774 (2012).

${ }^{15}$ M. Guehenec, V. Tishkova, S. Dagreou, F. Leonardi, Ch. Derail, P. Puech, F. Pons, F. B. Gauthier, P. H. Cadaux, and W. Bacsa, "The effect of twin screw extrusion on structural, electrical, and rheological properties in carbon nanotube poly-ether-ether-ketone nanocomposites," J. Appl. Polym. Sci. 129, 2527-2535 (2013).

${ }^{16} \mathrm{See}$ http://industrial.vestakeep.com/sites/dc/Downloadcenter/Evonik/Product/ VESTAKEEP/en/product-information/VESTAKEEP_2000P_Product_ information.pdf for product information VESTAKEEP ${ }^{\circledR}$ 2000P (accessed 20 January 2014).

${ }^{17}$ See http://www.isis.stfc.ac.uk/ for ISIS Facility information.

${ }^{18} \mathrm{See} \mathrm{http://www.mantidproject.org/} \mathrm{for} \mathrm{Manipulation} \mathrm{and} \mathrm{Analysis} \mathrm{Toolkit}$ information.

${ }^{19}$ G. D. Wignall and F. S. Bates, "Absolute calibration of small-angle neutron scattering data," J. Appl. Crystallogr. 20, 28-40 (1987).

${ }^{20}$ M. C. Kuo, C. M. Tsai, J. C. Huang, and M. Chen, "PEEK composites reinforced by nano-sized $\mathrm{SiO} 2$ and $\mathrm{Al} 2 \mathrm{O} 3$ particulates," Mater. Chem. Phys. 90, 185-195 (2005).

${ }^{21}$ D. J. Blundell and B. N. Osborn, "The morphology of poly(aryl ether ether ketone)," Polymer 24, 953-958 (1983).

${ }^{22}$ J. R. Sarasu, P. M. Remiro, and J. Pouyet, "Effects of thermal history on mechanical behavior of PEEK and its short-fiber composites," Polym. Compos. 17(3), 468-477 (1996).

${ }^{23}$ C. Rong, G. Ma, S. Zhang, L. Song, Z. Chen, G. Wang, and P. M. Ajayan, "Effect of carbon nanotubes on the mechanical properties and crystallization behavior of poly (ether ether ketone)," Compos. Sci. Technol. 70, 380-386 (2010).

${ }^{24}$ A. C. Ferrari and D. M. Basko, "Raman spectroscopy as a versatile tool for studying the properties of graphene," Nat. Nanotechnol. 8, 235-246 (2013).

${ }^{25}$ L. G. Cançado, A. Jorio, and M. A. Pimenta, "Measuring the absolute Raman cross section of nanographites as a function of laser energy and crystallite size," Phys. Rev. B 76, 064304 (2007).

${ }^{26}$ B. H. Stuart, "A Fourier transform Raman spectroscopy study of the crystallisation behaviour of a poly(ether ether ketone)/poly(ether sulphone) blend," Spectrochim. Acta, Part A 53, 107 (1997).

${ }^{27}$ B. H. Stuart, "Polymer crystallinity studied using Raman spectroscopy," Vib. Spectrosc. 10, 79-87 (1996).

${ }^{28}$ R. R. Nair, P. Blake, A. N. Grigorenko, K. S. Novoselov, T. J. Booth, T. Stauber, N. M. R. Peres, and A. K. Geim, "Fine structure constant defines visual transparency of graphene," Science 320(5881), 1308 (2008). 
${ }^{29}$ M. V. Shuba, G. Y. Slepyan, S. A. Maksimenko, C. Thomsen, and A. Lakhtakia, "Theory of multiwall carbon nanotubes as waveguides and antennas in the infrared and the visible regimes," Phys. Rev. B 79, 155403 (2009).

${ }^{30}$ A. Bassil, P. Puech, G. Landa, W. Bacsa, H. Hubel, D. J. Dunstan, S. Barrau, Ph. Demont, C. Lacabanne, and E. Perez, in Enhanced Raman Signal of $\mathrm{CH} 3$ on Carbon Nanotubes (Mater. Res. Soc. Symp. Proc., 2004), p. 858.
${ }^{31}$ A. C. Brosse, S. Tencé-Girault, P. M. Piccione, and L. Leibler, "Effect of multi-walled carbon nanotubes on the lamellae morphology of polyamide6," Polymer 49, 4680-4686 (2008).

${ }^{32}$ B. Hammouda, D. G. Reichel, and C. J. Wolf, "Neutron scattering from PEEK," J. Macromol. Sci. Phys. B 27, 445-454 (1988).

${ }^{33}$ M. Tsudi, H. Kawamura, A. Kawagushi, and K. Katayama, "TEM studies on solution-grown crystals of Poly(aryl-ether-ether-ketone) (PEEK)," Bull. Inst. Chem. Res. Kyoto Univ. 67, 77-88 (1989). 